\title{
Sperm storage and artificial insemination in honey bees (Apis mellifera L.)
}

\author{
Arda Onur Özkök ${ }^{1 *}$, Murat Selçuk ${ }^{2}$ \\ ${ }^{1}$ Suluova Vocational School, Amasya University, Amasya/Turkey \\ ${ }^{2}$ Department of Artificial Insemination, Faculty of Veterinary Medicine, Ondokuz Mayıs \\ University, Samsun/Turkey
}

\begin{abstract}
To obtain the expected yield from a honeybee colony, queen bee is required to have high egg capacity, the colony is also expected to be resistant to diseases, to have a low tendency for swarming, to be resistant to looting, and to be able to adapt to the climatic conditions of the region. In this context, it is important to protect the pure bee races and to improve them by conducting breeding research. To maintain the high yield aspect of honeybee colony, the queen bee needs to be replaced at most every 2 years. Queen bee becomes adult in as short as 16 days after hatching, and mating is realized in the air outside the colony, which makes it difficult to preserve the genetic line of the queen bee. At this point, artificial insemination and protection of gene resources become important. Honey bee (Apis mellifera L.) sperm can be stored for short and long periods. However, due to the delicate structure and biology of honey bee sperm, the high success rate in mammals could not be achieved in storing bee sperm. Due to the genetic damage exposed during the freezing of honey bee sperm, longterm storage difficulties are experienced. In addition, the concentration, motility and viability of spermatozoa decrease due to the short-term storage and storage conditions. In the breeding studies in the same region, after a period of time, gene resources decrease, and accordingly, the risk of inbreeding occurs. Instead of replacing the bee colonies that are at risk of inbreeding, a new different genome addition to the colony whose current yield characteristics are known can be made through the sperm storage of other colonies. Thanks to the long-term storage of sperm, long-period genetic studies can be carried out as in mammals, which is important for improving yield characteristics genetically. In addition, the long-term storage of honeybee sperm is a hope for the protection of regional races that are in danger of extinction due to unconsciousness and improper breeding policies.
\end{abstract}

Article History

Received 19.12.2019

Accepted 30.01.2020

\section{Keywords}

Artificial insemination, Freezing, Honeybee, Sperm

${ }^{1}$ Correspondence: arda.ozkok@amasya.edu.tr 


\section{Introduction}

In artificial insemination, the great accomplishments that can be repeated has been achieved (Cobey, 2007). Recent studies in the field of artificial insemination, especially in bees, and the benefits which artificial insemination provides are attracting great interest. In the past, artificial insemination in bee was difficult for a breeder, but it is now easily available, and there are many interested breeders. However, it is necessary to have suitable colonies to take advantage of honey bees (Apis mellifera L.) to increase their yield, to make genetic progress and to do breeding studies with the help of artificial insemination. To prevent inbreeding and diseases caused by the queen bee, it is necessary to renew the queen by obtaining the proper one from the colonies of the desired races and desired characteristics. It's a serious problem to just depend on our environment in so sensitive issues. Thus, the storage of honey bee sperm is the key to solve such problems. Since the 1970s, many different methods have been developed for freezing and thawing honey bee sperm, and studies are still being conducted (Hopkins and Herr, 2010).

\section{Colony Members of Honey Bees}

Honey bees are social insects that live together. A honey bee colony has 3 types of individuals: worker bee, drone, and queen (Genç and Dodoloğlu, 2002).

\subsection{Work Bee}

The worker bee and queen are female. They are born from fertilized eggs. Their chromosomes are diploid. The colony's greatest labor force is worker bees. They have many tasks in the colony such as hive cleaning, wax production, royal jelly production, care and feeding of the offspring and queen, hive guard, providing nectar, pollen, propolis, and ripening of honey (Genç and Dodoloğlu, 2002).

\subsection{Queen}

The queen determines the future of the colony. It lays eggs for the continuity of the colony and manages the colony with its pheromones. Other colony individuals are fed royal jelly for the first three days after hatching, and then honey and pollen, while the queen is fed royal 
jelly until the end of its life. A young queen can lay an average of as many as 1500-2000 eggs per day. It lays two kinds of eggs, fertilized and unfertilized. The young queen lays fertilized eggs on the worker bee honeycomb, while lays unfertilized eggs on the cells of the drones that are larger males. During mating, the queen transfers the inherited characteristics that it receives from the drone to the colony by combining them with their own hereditary characteristics. Environmental interactions with inherited traits observed in worker bees are reflected as the value of the colony. This is why it is vital for a beekeeper to breed quality bees. Female reproductive organs are a pair of ovaries, a pair of lateral oviducts, a large oviduct formed by the combination of the lateral oviducts, spermatheca where sperm is stored, spermatheca canal, and vagina (Genç and Dodoloğlu, 2002).

\subsection{Drones}

They have 16 chromosomes, i.e. they are haploid. They develop from unfertilized eggs. Their only mission in the colony is to mate (Winston, 1987). They are of great genetic importance because they are haploids (Laidlaw, 1979). The drone has a pair of testicles, a pair of vas deferens, a pair of mucus gland, a pair of ductus ejaculatorii as sexual organs (Den boer et al., 2009). Endophallus is also the outward part of the reproductive organs (Koeniger, 1990).

\section{Breeding of the Queen}

Queen breeding is divided into two as the natural ways of breeding and controlled queen breeding. Breeding by natural ways occurs in the form of loss of the queen, swarming, and renewal of the queen. Although there are many methods in controlled beekeeping, the most commonly used method is the Doolittle method (Vatansever, 2004). The queen loss or Doolittle method is used for breeding quality queens for artificial insemination purposes.

\subsection{Queen Breeding with Queen Loss}

Frames with larvae less than 3 days old are placed in the hive without the queen. According to population size, the colony is divided into several hives. In this way, each colony produces a queen. It is an easy method and costs less. But the queen may be lowquality (Vatansever, 2004). 


\subsection{Doolittle Method}

It is the transfer of 1-day-old young larvae into artificially prepared special queen-cell molding tools. The queen-cell molding tools are attached to the molds placed on an artificially prepared frame. The queen of a strong hive is taken 3 days before the transfer and the colony is left without a queen. Before the transfer, all open-off frames in the colony where the queen has been taken away are removed. Meanwhile, present royal jelly in the cells made by the bees to transform larvae into the queen is taken. The taken royal jelly is placed at sufficient amounts in the artificial queen-cell molding tool prepared for transfer, thus increasing the chance of success of the transfers. A suitable frame with 1-day-old larvae is taken from the breeding colony for transfer. Young larvae are carefully transferred into artificial queen-cell molding tools. Vaccination must be performed on the larvae's royal jelly. The frame of the hive in which transfer is done is given to the pre-prepared queenless starter hive, i.e. the starter colony (Vatansever, 2004).

The starter colony is fed with abundant pollen cakes and syrup. After the transfer frame stays 24-36 hours here, they are taken to the finisher colony. The finisher colony is the strong colony with the queen and 2-3 honeypot. The queen stays downstairs in the brood chamber and is not allowed to go out to the honey chamber. It is placed between the vaccination frames that are about to be left and the frames where young larvae are in. Queens that will emerge 11 days after vaccination are taken to the incubator or transferred to pre-prepared queenless mating core hives (Vatansever, 2004).

\section{Maturation of the Drone}

Honey bee development takes place in 4 stages. These are eggs, larvae, pupae and adults (Vatansever, 2004). The drone undergoes sexual maturity within eight to ten days after leaving the pupae. During this time, the reproductive system and the maturation process of the sperm develop (Colonello-Frattini and Hartfelder, 2009). This stage is managed by the bee's endocrine system. Juvenile hormone is effective in the transform of insects from larva to pupae and adults. It also encourages flying. Corpora allata, the gland that secretes the juvenile hormone, is activated during the maturation period (Giray and Robinson, 1996; Tozetto et al., 1997). 


\section{Mating of the Drone}

In honey bees, mating occurs in the air. When the drone takes a mating position, the endophallus is pushed back and go out as a result of the pressure generated through the contraction of the abdominal muscles by hemolymph (Woyke and Ruttner, 1958). The cornua bend downwards (Woyke, 1955). When the endophallus partially rotates within the mating organ of the queen, the drone is paralyzed (Woyke, 2011). When the drone is separated from the queen, a part of the endophallus remains in the needle compartment of the queen. This piece is called the mating sign. The mating sign is a chitin layer of the endophallus containing mucus (Woyke, 2011). With the increase of mucus, the sperm is transferred to the queen. As the drone leaves the queen, the mating sign is also pushed into the needle of the queen (Woyke, 2008). Mucus is slightly alkaline and becomes viscous during maturation of the drone (Moors et al., 2005). Protein synthesis takes place in the lumen of the mucus gland. These proteins are essential for sexual maturity. When the endophallus is torn, the mucus in the part of the queen and the mating sign solidify, forming a mating stopper. Thanks to the stopper created by mucus, other drones are quickly prevented from mating (Koeniger and Koeniger, 2000). There is bulbus gland secretion between the mucus secretion and sperm (Colonello and Hartfelder, 2003). When the endophallus turns outward, it is torn, and the drone is separated from the queen by transmitting the sperm, secretion of the bulbus gland, cornu gland and mucus mating sign into the queen (Collins et al., 2006).

The sperm produced in the testicle is transmitted by the contraction of the testicular vesicle, while a large amount of seminal secretion is taken from the accessory gland. The accessory gland also produces the mucus that makes up the mating stopper (Den Boer et al., 2009).

\section{Sperm Collecting from Drone}

Drones flying before giving sperm, thus warming up, provide an advantage during sperm collecting (Collins, 2003). Wegener and Bienefeld (2012) used the method described by Harbo (1979). The genital organ, which is stimulated by the pressure applied to thorax and abdomen of the drone which reaches the desired maturity to give the sperm, turns outwards and appears. Sperm is seen in smaller amounts on the mucus layer. Sperm is collected with the help of a special syringe developed for this purpose (Harbo, 1974). The syringe contains 
sterile saline solution. A sufficient amount of antibiotics is added to the saline solution and necessary precautions against contamination are taken. In addition, syringes and their parts are treated with $70 \%$ alcohol and then cleaned with pure water (Paillard et al., 2017). There are many instructions related to saline solution. For example, Paillard et al. (2017) used 1000 $\mathrm{mL}$ of pure water, $10 \mathrm{~g}$ of sodium chloride and $0.25 \%$ dihydrostreptomycin.

\section{Sperm Examination in Honey Bees}

\subsection{Motility Test}

In an Eppendorf tube, $0.5 \mathrm{~mL}$ of $0.9 \% \mathrm{NaCl}$ and sperm are mixed. Subjective evaluation is made (Gontarz et al., 2016). According to Taylor et al. (2009), evaluations are made in the form of percentages $(0,20,40,60,80,95)$.

\subsection{Concentration of Spermatozoon}

To calculate the number of spermatozoon in the spermatheca, the queens are killed and dissected and their spermathecae are removed. One $\mathrm{mL}$ of dilution (Kiev solution, saline...), 4 $\mathrm{mL}$ of cold water are gently ground with the help of a mortar. Also, 8 squares of the hemocytometer are filled with approximately $10 \mu \mathrm{L}$ of the taken sample, and spermatozoa are appropriately counted. The obtained value is multiplied by 50000 and the approximate result is estimated (Gül et al., 2017).

For arranging the density of spermatozoon, $1 \mu \mathrm{L}$ of sperm is diluted with $1 \mathrm{~mL} \mathrm{Kiev}$ solution. The specimen added to the hemocytometer is examined by light microscopy at 400x magnification. After counting the spermatozoa in the four middle square, the overall spermatozoa are calculated by multiplying the obtained value and 10 and the amount of dilution (Cobey et al., 2013).

\subsection{Morphological Examination}

\subsubsection{Water test}


One $\mu \mathrm{L}$ of sperm is added to $250 \mu \mathrm{L}$ of pure water at room temperature, and after waiting 5 minutes, a drop is taken on the lam on the phase-contrast microscope and examined at 400x magnification. It is evaluated in terms of morphological differences (Nur et al., 2012).

\subsubsection{Staining of spermatozoon}

In particular, it helps the acrosome, head, and nucleus to look better and the tail to be structurally evaluated. Two methods have been used in the studies for this purpose. Staining with $\mathrm{AgNO}_{3}$ (silver nitrate) aids in the evaluation of chromatin proteins of acidic structure. Silver nitrate is an alkaline dye (Andraszek and Smalec, 2011). More sufficient results are obtained from it compared to the eosin and gentian violent complex. This acidic dye stains spermatozoa well and is used to distinguish morphological characteristics (Kontracki et al., 2005).

\subsection{Examination of the Dead and Living Spermatozoa}

Collins and Donoghue (1999) mixed 2-3 $\mu \mathrm{L}$ of sperm with $1 \mathrm{~mL}$ of Kiev solution (Dglucose, $0.3 \mathrm{~g}$; potassium chloride, $0.41 \mathrm{~g}$; sodium bicarbonate, $0.21 \mathrm{~g}$; sodium citrate-2 hydrate, $2.43 \mathrm{~g}$; in $100 \mathrm{~mL}$ pure water) as described by Moritz (1984), and after diluting it with $200 \mu \mathrm{L}$ SYBR-14 and Propidium iodide, it is kept at room temperature for 15 minutes. It is examined under a microscope at 40x magnification. SYBR-14 adheres to nucleic acid and stains it green, while Propidium Iodide also distinguishes dead cells by staining them red.

For the purpose of dead-living cell examination of frozen sperm, Gül et al. (2017) added 1 $\mu \mathrm{L}$ of SYBR-14 and $1 \mu \mathrm{L}$ of propidium iodide to $1 \mu \mathrm{L}$ of sperm for every $50 \mu \mathrm{L}$ of DMSO, i.e. 4 microliters of SYBR-14 and 4 microliters propidium iodide for every $200 \mu \mathrm{L}$ of solution, and after incubating $30{ }^{\circ} \mathrm{C}$ in 10 minutes, they examined the specimens by taking a sample of $5 \mu \mathrm{L}$.

\section{Storing Honey Bee Sperm}

After mating, spermatozoa of the honey bee can live for a long time in the spermatheca of the queen. The oxygenated spermatheca contains the protein, sugar, and antioxidants necessary for the survival of spermatozoa (Phiancharoen et al., 2004). A suitable buffer 
diluter should have around $8.5 \mathrm{pH}$ and the necessary amino acids, sugar and antibiotics (Moritz, 1984).

\subsection{Short-Term Storage of Honey Bee Sperm}

Fresh sperm can be stored in a capillary glass tube. There should be some diluter on both sides of the tube. It can be stored by closing the two ends of the tube so that sperm and air are kept in the middle (Burley et al., 2008). If the sperm stored for the purpose of eliminating harmful effects for the queen is diluted, it is centrifuged in $1.5 \mathrm{~mL}$ eppendorf tube for $10 \mathrm{~min}$ at $1000 \mathrm{rpm}$, so the sperm is re-separated (Wegener et al., 2014). Cobey (2007) argued the negative effects of temperature on sperm when storage temperature was below $10{ }^{\circ} \mathrm{C}$ and above $32{ }^{\circ} \mathrm{C}$, based on the study of Harbo and Williams (1987).

\subsection{Long-Term Storage of Honey Bee Sperm}

The sperm diluted with the proper diluter is closed with air on both sides of the pipette. It is then cooled to $+4^{\circ} \mathrm{C}$ in two hours to protect the sperm from cold shock. It is then cooled to $40^{\circ} \mathrm{C}$ by decreasing $3^{\circ} \mathrm{C}$ per minute with the help of a special cooler and then transported into $-196^{\circ} \mathrm{C}$ liquid nitrogen. When reused, it is dissolved by waiting $30 \mathrm{sec}$. at $+37^{\circ} \mathrm{C}$ (Paillard et al., 2017). In a study, the sperm cooled quickly to $0^{\circ} \mathrm{C}$ was transported into liquid nitrogen ($\left.196^{\circ} \mathrm{C}\right)$ (Hopkins and Herr, 2010).

According to Taylor et al. (2009), after diluting $10 \mathrm{~mL}$ of sperm by $1 / 5$, it is cooled to a temperature of $5{ }^{\circ} \mathrm{C}$ in 1-hour in the water bath. After waiting for equilibrium at $+5{ }^{\circ} \mathrm{C}$ for 2 hours, the straws are filled with $0.25 \mathrm{cc}$ of this dilution. The two sides of the straws are covered with air and some diluent or a substance such as polyvinyl alcohol or hot press. After freezing it in liquid nitrogen vapor at $-110{ }^{\circ} \mathrm{C}$ for $10 \mathrm{~min}$, it is stored in $-196^{\circ} \mathrm{C}$ liquid nitrogen.

When honey bee sperm kept at $-196^{\circ} \mathrm{C}$ for 48 hours, the fertilized queen is seen to lay more drones than worker bee (Harbo, 1977). In light of this information, many different cryoprotectant agents are used. Gül et al. (2017) emphasized that the best result was obtained from the mixture of $60 \%$ sperm, $10 \%$ DMSO (dimethyl sulfoxide) and $30 \%$ saline solution described by Harbo (1979). Depending on the storing time of sperm, the number of worker bees decreased. Cobey (2007) stated that there was a decrease in the number of worker bees 
after the long-term storage of sperm described by Harbo (1979). The cause of this situation is the genetic damage of sperm due to freezing, as stated by Harbo (1981).

In order for honeybee sperm to be stored for a long time, appropriate storage techniques are needed (Cobey, 2007). Factors affecting the success of freezing methods include toxicity of cryoprotectants, freezing speed, temperature sensitivity and cold shock (Hopkins and Herr, 2010).

Whether cryoprotectants caused cell death has been investigated. DMSO is the least damaging agent among other cryoprotective. Also, 95\% motility is observed at room temperature in 1-hour; and 35\% living cells are observed in distillation with glycerol, but no motility is observed. In the mixture with DMSO and glycerol, it is observed that living spermatozoa are around $65 \%$ in 1-hour. When the water baths of spermatozoa at temperatures of $30,35,40$ and $45^{\circ} \mathrm{C}$ were used, there was no significant difference in the thawing of sperm up to $40^{\circ} \mathrm{C}$ (Hopkins and Herr, 2010). The egg yolk, which is used successfully in mammals, is not preferred because it clogs the sexual canals of the queen. Frozen and thawed sperm are used after centrifugation, but spermatozoa are damaged during this process. Honey bee spermatozoa are very delicate and sensitive. Therefore, the centrifuge process is more successful in fresh sperm. Success is expressed as the percentage of worker bees in the eggs of inseminated queens (Wegenner et al., 2014).

Honey bee sperm can be stored at temperatures between $+16{ }^{\circ} \mathrm{C}$ and $-196{ }^{\circ} \mathrm{C}$. In a study conducted for this purpose, the viability rates of sperm, which was stored at temperatures of $16{ }^{\circ} \mathrm{C}$ and $-196^{\circ} \mathrm{C}$ and used by being centrifuged and not centrifuged at different time intervals, were examined. As a result, all spermatozoa stored for a long time at $16{ }^{\circ} \mathrm{C} \mathrm{died}$. In frozen and thawed samples, the viability rate before centrifuge was $78 \pm 3 \%$, while after centrifuge it was $75 \pm 3 \%$. The centrifuge process reduces the viability of sperm.

In the study, according to the number of spermatozoa in the spermatheca, half of the 36 queens were inseminated after centrifugation and the other half were inseminated without centrifugation. Since all spermatozoa stored for a long time at $16{ }^{\circ} \mathrm{C}$ died, the evaluation was conducted through the spermatozoa stored at $-196^{\circ} \mathrm{C}$. When the spermathecas of the queens were examined, alive spermatozoa were observed at a rate of $82 \%$, and $13 \%$ of them were found to have empty spermatheca. Spermatozoon numbers were determined between about 
5.000 and 1.500.000. Spermatozoa viability was found between $10 \%$ and $71 \%$. In the same study, when the situation between temperature and sperm viability was examined, it was observed that the viability rate of the sperm stored at $+16^{\circ} \mathrm{C}$ in 90 days $(77 \% \pm 5)$ was higher than the viability rate of the sperm stored at $-196^{\circ} \mathrm{C}(61 \% \pm 5)$. Sperm viability at $+16^{\circ} \mathrm{C}$ $(69 \pm 8 \%)$ and $-196^{\circ} \mathrm{C}(64 \pm 8 \%)$ approached each other at 180 days, but all of the spermatozoa stored at $+16^{\circ} \mathrm{C}$ for 330 days died out (Paillard et al, 2017).

In a study of different cryoprotective and dilution rates, 3 different cryoprotective (DMSO, DMA, glycerol) and 5 different dilution rates (1:1, 3:1, 6:1, 9:1, 12:1) were used. DMSO was found to be more successful than other agents. As the sperm dilution rate was increased, the sperm's survival rate also increased. When the amount of dilution increases, it becomes easier for cryoprotectant diluent to be diffused into the cell and wrapped spermatozoa better (Taylor et al., 2009).

Sodium, potassium, calcium, magnesium ions are found in bee sperm. These ions, also found in mammals, are essential for maintaining sperm motility and viability. Hence they are required to be present in the diluent (Moritz, 1984; Elits, 2005). $\mathrm{HCO}_{\overline{3}}$ (bicarbonate), which is found in seminal fluids in mammalian animals and is essential for sperm functions, is important. $\mathrm{HCO}_{3}$ increases intracellular $\mathrm{pH}$. It stimulates motility by causing an increase in $\mathrm{Ca}^{+2}$ and cAMP (cyclic adenosine monophosphate) between cells (Gagnon and Lamirande, 2006). It was determined that sperm motility was higher in diluents where bicarbonate and potassium were higher (Taylor et al., 2009).

Taylor et al. (2009) studied the effects of different diluents on sperm and compared between diluents with and without bicarbonate, and found that after freezing and thawing, the rate of viability in the sperm diluted with bicarbonate-containing diluents was higher. In the study, a bicarbonate-free diluent with a $\mathrm{pH}$ of about 9.7 that is the $\mathrm{pH}$ of the spermatheca of a queen was found to be more successful. This result supported the study of Camargo (1975).

Antioxidants can prevent damage to the cell due to oxidative stress by different mechanisms (Rahal et al., 2014). Catalase, a natural antioxidant, is important for the viability of spermatozoa (Collins et al., 2004). 


\section{Insemination of the Queen}

After the sperm is collected, the queen is anaesthetised with carbon dioxide $\left(\mathrm{CO}_{2}\right)$. Queen is placed upside down in the tube. The amount of $\mathrm{CO}_{2}$ that will come to the queen tube is adjusted. The main reasons for the $\mathrm{CO}_{2}$ application are to prevent the queen from moving during insemination and to enable the queen to lay eggs in a short time after insemination. During insemination, after the queen is anaesthetised, it is fixed in the appropriate position to the insemination device. For passing the vaginal valve in the queen, fixation of the queen holder with the injector needle at an angle of around ${ }^{\circ} 45$ provides an advantage. The vagina emerges with the help of a special pair of hooks. One of the hooks is the abdominal hook, and the other holds the needle. By lifting the hook holding the needle slightly upward, the position is created for artificial insemination. The injector end of the artificial insemination device is gently directed to the vaginal opening. The injector end of the insemination device is gently directed up and forward, and the vaginal valve is passed. Also, $8-12 \mu \mathrm{L}$ of sperm that must be transplanted is given to the queen (Cobey et al., 2013). Cobey (2007) suggested that sperm is stored by flowing into the lateral oviduct canal and then passing into the spermatheca, which Koenigerin (1986) stated it before regarding the path of sperm in artificial insemination of honey bees.

Sperm can be used in artificial insemination in honey bees by storing them for long and short periods. Studies show that artificial insemination with short-term stored sperm gives more successful results. In addition, sperm taken from male honey bees for artificial insemination does not include some disease risks found in mammals (Colins, 2000).

Cobey (1998) found that naturally mated bees have a close life span to that of queens fertilized by artificial insemination. Wilde (1994) stated that naturally mated bees start to lay egg earlier than bees with artificial insemination. Cobey (2007) published a review article comparing the queens with natural mating and artificial insemination, Harbo (1986) found more spermatozoa in naturally mating bees than those fertilized by artificial insemination.

In addition, the study found that the artificial insemination in queens was successful in terms of colony management and resistance to the difficulties in natural conditions. Artificial insemination in honeybees has provided a great advantage especially for bee breeding studies (Cobey et al., 2013). 


\section{Conclusion}

Artificial insemination in honey bees has become an increasingly important area in the world. Beekeepers are aware of the advantages of artificial insemination in controlled beekeeping. In the studies related to the short and long storage of honeybee sperm, the desired results as sufficient as in mammals have not been achieved. But there has been great progress recently. These developments have been a hope for the development of Turkey's and the World's beekeeping. Thanks to the freezing and long-term storing of honeybee sperm, yield characteristics can be increased in controlled beekeeping in the near future, just as in some mammalian animal breedings. Longer-term scheduled genetic studies can be done. But these studies are expected to be conducted consciously to be useful. That is why, in this case, it is possible to protect regional races, while gene pollution is likely to spread more quickly.

\section{References}

Andraszek, K., Smalec, E. 2011. The use of silver nitrate for the identification of spermatozoon structure in selected mammals, Canadian Journal of Animal Science, 91(2): 239-246.

Burley, L.M., Fell, R D., Saacke, R.G. 2008. Survival of honey bee (Hymenoptera: Apidae) spermatozoa incubated at room temperature from drones exposed to miticides, Journal of Economic Entomology, 101(4): 1081-1087.

Camargo, C.A. 1975. Biology of the spermatozoon of Apis mellifera L. influence of diluents and $\mathrm{pH}$, Journal of Apicultural Research, 14(3-4): 113-118.

Cobey, S. 1998. A comparison of colony performance of instrumentally inseminated and naturally mated honey bee queens, Proceedings American Bee Research Conference, Colorado Springs, CO, American Bee Journal, 138: 292.

Cobey, S.W. 2007. Comparison studies of instrumentally inseminated and naturally mated honey bee queens and factors affecting their performance, Apidologie, 38(4): 390-410.

Cobey, S., Tarpy, D., Woyke, J. 2013. Standard methods for instrumental insemination of Apis mellifera queens, Journal of Apicultural Research, 52(4): 1-18.

Collins, A.M., Donoghue A.M. 1999. Viability assessment of honeybee, Apis mellifera, sperm using dual fluorescent staining, Theriogenology, 51(8): 1513-1523.

Collins, A.M. 2000. Survival of honey bee (Hymenoptera: Apidae) spermatozoa stored at above-freezing temperatures, Journal of Economic Entomology, 93(3): 568-571.

Collins, A.M. 2003. A scientific note on the effect of centrifugation on pooled honeybee semen, Apidologie, 34(5): 469-470.

Collins A.M., Williams V., Evans J.D. 2004. Sperm storage and antioxidative enzyme expression in the honey bee, Apis mellifera, Insect Molecular Biology, 13(2): 141-146.

Collins A.M., Caperna, T.J., Williams, V., Garrett, W.M., Evans, J.D. 2006. Proteomic analyses of male contributions to honey bee sperm storage and mating, Insect Molecular Biology, 15(5): 541-549.

Colonello, N.A., K. Hartfelder. 2003. Protein content and pattern during mucus gland maturation and its ecdysteroid control in honey bee drones, Apidologie, 34(3): 257-267. 
Colonello-Frattini, N.A., Hartfelder, K. 2009. Differential gene expression profiling in mucus glands of honey bee (Apis mellifera) drones during sexual maturation, Apidologie, 40(4): 481-495.

Den Boer, S.P.A., Boomsma, J.J., Baer, B. 2009. Honey bee males and queens use glandular secretions to enhance sperm viability before and after storage, Journal of Insect Physiology, 55(6): 538-543.

Elits, B.E. 2005. Theoretical aspects of canine semen cryopreservation, Theriogenology, 64(3): 692-697.

Gagnon, C., de Lamirande E. 2006. Controls of sperm motility. In: De Jonge, C.J., Barratt, C.L.R. (Eds). The Sperm Cell. Cambridge University Press. pp. 108-33.

Genç, F., Dodoloğlu, A. 2002. Arıcılığın temel esasları. Atatürk Üniversitesi Ziraat Fakültesi Yayınları, Atatürk Üniversitesi Basımevi, Erzurum. Yayın No: 166.

Giray, T., Robinson, G.E. 1996. Common endocrine and genetic mechanisms of behavioral development in male and worker honey bees and thee volution of division of labor, Proceedings of the National Academy of Sciences, 93(21): 11718-11722.

Gül, A., Şahiner, N., Onal, A.G., Hopkins, B.K., Sheppard, S. W. 2017. Effects of diluents and plasma on honey bee (Apis mellifera L.) drone frozen-thawed semen fertility, Theriogenology, 101: 109-113.

Gontarz, A., Banaszewska, D., Gryzinska, M., Andraszek, K. 2016. Differences in drone sperm morphometry and activity at the beginning and end of the season, Turkish Journal of Veterinary and Animal Sciences, 40(5): 598-602.

Harbo, J.R. 1974. A technique for handling stored semen of honey bees, Annals of the Entomological Society of America, 67(2): 191-194.

Harbo, J.R. 1977. Survival of honey bee spermatozoa in liquid-nitrogen, Annals of the Entomological Society of America, 70(2): 257-258.

Harbo, J.R. 1979. Storage of honey bee spermatozoa at $-196^{\circ} \mathrm{C}$, Journal of Apicultural Research, 18(1): 57-63

Harbo, J.R. 1981. Viability of honey bee eggs from progeny of frozen spermatozoa, Annals of the Entomological Society of America, 74(5): 482-486.

Harbo, J.R. 1986. Sterility in honey bees caused by dimethyl sulfoxide, Journal of Heredity, 77(2): 129-130.

Harbo, J.R., Williams J.L. 1987. Effect of above-freezing temperatures on temporary storage of honey bee spermatozoa, Journal of Apicultural Research, 26: 53-55.

Hopkins, B.K., Herr, C. 2010. Factors affecting the successful cryopreservation of honey bee (Apis mellifera) spermatozoa, Apidologie, 41(5): 548-556.

Koeniger, G. 1986. Reproduction and mating behavior. In: Rinderer, T.E. (Ed). Bee Breeding and Genetics. Academic Press. pp. 235-252.

Koeniger, G. 1990. The role of the mating sign in honey bees, Apis mellifera L.: does it hinder or promote multiple mating? Animal Behaviour, 39: 444-449.

Koeniger, N. and Koeniger, G. 2000. Reproductive isolation among species of the genus Apis, Apidologie, 31: 313-339.

Kondracki, S., Banaszewska, D., Mielnicka, C. 2005. The effect of ageon the morphometric sperm traits of domestic pigs (Sus scrofadomestica), Cellular \& Molecular Biology Letters, 10(1): 3-13.

Laidlaw, H.H. 1979. Contemporary queen rearing. Dadant and Sons Inc. Journal Printing Co. Carthaga. Illinois. USA.

Moors, L., Spaas, O., Koeniger, G. 2005. Morphological and ultra structural changes in the mucus glands of Apis mellifera drones during pupal development and sexual maturation, Apidologie, 36: 245-254. 
Moritz, R.F.A. 1984. The effect of different diluents on insemination success in the honeybee using mixed semen, Journal of Apicultural Research, 23(3): 164-167.

Nur, Z., Cakmak, S., Ustuner, B., Cakmak, I., Erturk, M., Abramson, C.L., Sagirkaya, H, Soylu, M.K. 2012. The use of hypo-osmotic swelling test, water test, and supra vital staining in the evaluation of drone sperm, Apidologie, 43: 31-38.

Paillard, M., Rousseau, A., Giovenazzo, P., Bailey, J.L. 2017. Preservation of domesticated honey bee (hymenoptera: apidae) drone semen, Journal of Economic Entomology, 110(4): 1412-1418.

Phiancharoen, M., Wongsiri, S., Koeniger, N., Koeniger, G. 2004. Instrumental insemination of Apis mellifera queens with hetero-and conspecific spermatozoa results in different sperm survival, Apidologie, 35(5): 503-511.

Rahal, A., Kumar, A., Singh, V., Yadav, B., Tiwari, R., Chakraborty, S., Dhama, K. 2014. Oxidative stress, pro oxidants, and antioxidants: the interplay, Hindawi Publishing Corporation, 2014: 1-19.

Taylor, M.A., Guzman-Novoa, E., Morfin, N., Buhr, M.M. 2009. Improving viability of cryopreserved honey bee (Apis mellifera L.) sperm with selected diluents, cryoprotectants, and semen dilution ratios, Theriogenology, 72(2): 149-159.

Tozetto, S.O., Rachinsky, A., Engels, W. 1997. Juvenile hormone promotes flight activity in drones (Apis mellifera carnica), Apidologie, 28: 77-84.

Vatansever, H. 2004. Arı yetiştiriciliği ve hastalıkları, Ankara.

Wegener, J., Bienefeld, K. 2012. Toxicity of cryoprotectants to honey bee semen and queens, Theriogenology, 77(3): 600-607.

Wegener, J., May T., Kamp, G., Bienefeld, K. 2014. New methods and media for the centrifugation of honey bee (Hymenoptera: Apidae) drone semen, Journal of Economic Entomology, 107(1): 47-53.

Wilde, J. 1994. The effects of keeping queen honey bees after instrumental insemination on their performance, Acta Academiae Agricultural Technicae Olstenensis, Zootechnica 39: 153-166.

Winston, M.L. 1987. The biology of the honey bee. Harvard University Press: London, UK.

Woyke, J. 1955. Multiple mating of the honey bee queen (Apis mellifera L.) in one nuptial flight, Bulletin of the Polish Academy of Sciences, 3(5): 175-180.

Woyke, J., Ruttner, F. 1958. An anatomical study of the mating process in the honeybee, Bee World, 39(1): 3-18.

Woyke, J. 2008. Why the eversion of the endophallus of honey bee drone stops at the partly everted stage and signifieance of this, Apidologie, 39(6): 627-636.

Woyke, J. 2011. The mating sign of queen bees originates from two drones and the process of multiple mating in honey bees, Journal of Apicultural Research, 50(4): 272-283. 